\title{
A GENERALIZATION OF WEIGHTED BILINEAR HARDY INEQUALITY
}

\author{
BOUHARKET BENAISSA and MEHMET ZEKI SARIKAYA
}

\begin{abstract}
In this paper, we give some new generalizations of the weighted bilinear Hardy inequality by using weighted mean operators $S:=(S f)_{g}^{w}$, where $f$ nonnegative integrable function with two variables on $\triangle=(0,+\infty) \times(0,+\infty)$, defined by

with

$$
S(x, y)=\int_{a}^{x} \int_{c}^{y} \frac{w(t) w(s)}{W(t) W(s)} g(f(t, s)) \mathrm{d} s \mathrm{~d} t,
$$

$$
W(z)=\int_{0}^{z} w(r) \mathrm{d} r, \quad \text { for } z \in(0,+\infty),
$$

where $w$ is a weight function and $g$ is a nonnegative continuous function on $(0,+\infty)$.
\end{abstract}

MSC 2010. 26D15, 26D10.

Key words. Hölder's inequality, Hardy-Type Integral Inequality, weight function.

\section{REFERENCES}

[1] M.I.A. Canestro, P.O. Salvadora and R. Torreblanca, Weighted bilinear Hardy inequalities, J. Math. Anal. Appl., 387 (2012), 320-334.

[2] Z.Q. Chen and R. Song, Hardy inequality for censored stable processes, Tohoku Math. J., 55 (2003), 439-450.

[3] L. Grafkos, X. Li and D. Yang, Bilinear operators on Herz-type Hardy spaces, Trans. Amer. Math. Soc., 350 (1998), 1249-1275.

[4] Z. Hanjs, C.E.M. Pearce and J. Pecaric, Multivariate Hardy-type inequalities, Tamkang J. Math., 31 (2000), 149-158.

[5] G.H. Hardy, Notes on some points in the integral calculus, Messenger of Mathematics, 57 (1928), 12-16.

[6] M. Krepela, Bilinear weighted Hardy inequality for non-increasing functions, Publ. Mat., 61 (2017), 3-50

[7] M. Krepela, Iterating bilinear Hardy inequalities, Proc. Edinburgh Math. Soc., 60 (2017), 955-971.

[8] S. Kumar, A Hardy-type inequality in two dimensions, Indag. Math. (N.S.), 20 (2009), $247-260$.

[9] A. Kufner, L. Maligranda and L.E. Persson, The prehistory of the Hardy inequality, Amer. Math. Monthly, 113 (2018), 715-732.

The authors thank the referee for his helpful comments and suggestions. The authors would like to thank DGRSDT.Algeria for the support of this research.

DOI: $10.24193 /$ mathcluj.2021.2.03 
[10] B.G. Pachpatte, On Hardy-type integral inequalities for functions of two variables, Demonstr. Math., XXVIII (1995), 239-244.

[11] E. Sawyer, Weighted inequalities for the two-dimensional Hardy operator, Studia Math., LXXXII (1985), 1-16.

[12] A. Wedestig, Weighted inequalities for the Sawyer two-dimensional Hardy operator and its limiting geometric mean operator, J. Inequal. Appl., 4 (2005), 387-394.

[13] K. Zhang, A bilinear inequality, J. Math. Anal. Appl. 271 (2002), 288-296.

[14] F. Zhao, Z. Fu and S. Lu, $M_{p}$ weights for bilinear Hardy operators on $R^{n}$, Collect. Math., 65 (2014), 87-102.

Received October 21, 2019

Accepted May 22, 2020
University of Tiaret, Algeria

Faculty of Material Sciences

Laboratory of Informatics and Mathematics

E-mail: bouharket.benaissa@univ-tiaret.dz https://orcid.org/0000-0002-1195-6169

Düzce University, Düzce, Turkey

Faculty of Science and Arts

Department of Mathematics

E-mail: sarikayamz@gmail.com

https://orcid.org/0000-0002-6165-9242 